\title{
A HUSSERLIAN PHENOMENOLOGICAL INVESTIGATION OF THE LIVED EXPERIENCE OF AN ART EDUCATOR AND CHILDREN
}

\section{Alan Wilson}

As the title suggests, my research utilizes phenomenological philosophy in a study of the experience which occurs during an art lesson. There are many studies in the field which have made use of phenomenology in one form or another. In fact, there are many phenomenologies. Philosophical journals abound with a variety of phenomenologies, as well as with a multitude of offshoots and hybrids. Yet most of the studies in art education, and a majority of phenomenological philosophers, pay homage to Edmund Husserl, often called the founder of phenomenology. The majority of philosophical thought which grows out of phenomenology can be traced back to Husserl, and it is for this reason that I decided to use Husserlian phenomenology as the philosophical grounding of my research.

The studies in the art education field which make use of a phenomenological methodology tend not to be Husserlian. In fact, I only found three which remained strictly within the phenomenology as conceived by Husserl. After reading some of Husserl's writing, it is easy to understand why so few studies remained Husserlian. Quite simply, Husserl's writing does not clearly express the complexities of his concepts. Discussions of the difficulty in understanding Husserl's intended meaning abound in the philosophical literature. Even some of the translators of his works, whose efforts allowed the original German versions to achieve a wider audience within the English-speaking world, complained about Husserl's style of writing. Undaunted by these obvious difficulties I read all the major works by Husserl, as well as those by critics, both benevolent and hostile. I became more than intrigued, yet less than obsessed. The more I read, 
the more I became convinced that in Husserlian phenomenology lay a valuable investigative methodology with a high degree of applicability to the field of art education. The specific area of the field I was particularly interested in, the art experience at the secondary level, seemed to me to be ideally suited to the open nature of Husserlian phenomenology.

Before I embark on a description of the actual research, what is needed is a clear definition of Husserlian phenomenology which may prove helpful, especially for those unfamiliar with this form of philosophy. I have discussed difficulties, and being more than interested in phenomenology as a method, but appropriate questions arise here: What is phenomenology, and can it be clearly and simply defined? I will not even begin to discuss the number of writers who have attempted to answer these simple questions. Instead, I offer a definition, which I believe is as clear as any I have come across. This is by Harry Reeder.

Phenomenology is a self-critical methodology for reflexively examining and describing the lived evidence (the phenomena) which provides a crucial link in our philosophical and scientific understanding of the world. (1986, p. 1)

Some key words in this definition need some explanation, a common feature in any attempt to interpret, explain, or define phenomenology. The following is a synopsis of Reeder's explanation. Self-critical means that phenomenology, apart from anything else, examines its own goals and methods in order to make explicit the strengths and weaknesses of the actual doing of phenomenology. Reflexive, here, indicates that an individual reflects upon his/her own experiences because phenomenology seeks to understand experience as it is lived. These lived-experiences constitute the phenomena which gives phenomenology its name. The evidence phenomenology seeks is discovered through lived-experience. Husserl always maintained that 
phenomenology is scientific. If science can be described as an attempt to understand man and the world, then phenomenology is scientific because it is a self-critical examination and description of experience. It attempts to understand the structures of experience, rather than the objects experienced. Because human experience provides evidence for our claims about the world, this experience is important to science.

Once I understood the nature of phenomenology in this way I thought it would provide a humanistic, experientially oriented investigative tool, well suited to inquiries into art education. My professional experience in the field of art education centers upon the secondary school level. Being involved with students in schools made me curious as to how they viewed art, what they learned, in short: the nature and quality of their art experiences. My research aim, simply stated, became to understand more completely the nature of art experiences at the secondary school level.

Once I settled upon phenomenology as a research method, and experiences in a certain situation as the research area, I sought out an appropriate school, teacher and students. The school eventually chosen is a school for the fine and performing arts which recently was established by a local school board. The teacher, principal and school board authorities endorsed my research proposal, and I chose a particualar lesson which occurred at a time convenient for all concerned.

When I arrived for the first lesson, I did not know this initial part of the investigation would take 12 lessons. I wanted to begin when the teacher introduced a new topic or lesson, and remain as long as it took to see the event reach a conclusion. The topic chosen by the teacher was an experimental painting based upon a sky theme. Initially, I observed the class from the back of the classroom and gathered data in the form of written description, audio tape recordings and photographs. During subsequent lessons I circulated 
among the students and sought their views of the event. These data served as a basis for the ensuing phenomenological description and analysis.

The obvious problem with this form of research becomes an accumulation of information which contains excessive detail. Choosing what is important and what is irrelevant becomes crucial to the nature of the investigation, as well as its final outcome. One of the tenets of phenomenological research is that the investigator attempts to be presuppositionless and remain completely open to the unfolding experience. One can imagine how much information this type of approach can generate. Clearly, much work is involved in sifting and sorting through the accumulated data. Areas of importance do not become clear until long after the event has passed, when the description is complete, and when the research enters the analysis stage. At this point, the researcher has become so familiar with the material that it becomes a relatively easy task to designate areas of importance and concentrate on them.

If the drawbacks can be overcome, the benefits of phenomenological research can be satisfying and rewarding. The researcher is secure in the knowledge that as far as it is possible, nothing in the researched area has been overlooked in terms of human experience. There are no restrictions to preconceived set plans or narrow methodologies. Moreover, built into phenomenological research is the flexibility to concentrate upon issues as they arise within the investigated experience. In other words, if the tediousness of the details can be tolerated and overcome, the rewards which follow will be a multi-layered, richly complex picture of human interaction and experience.

At the present time I have completed the research in the school, the descriptive writing of the event, and am finalizing a phenomenological analysis of the description. While the results are not complete, I do find that my familiarity with the materials has 
afforded me insights, some of which are predictable and some surprising. For example, during the 12 one-hour lessons, the aims of the students were different from those of their teacher. Is this surprising or predictable? Perhaps a little of both. I could have assumed the teacher had certain aims regarding the lesson, and the students would share these aims as their knowledge of the event grew, and as the event itself unfolded. What I found was that the teacher emphasized the process of art, whereas the students overwhelmingly strove for a product. I was also surprised by how flexible the teacher was in her approach. When results did not quickly come about from one tactic, instead of laboring on, another quickly was attempted. The lesson changed its direction a number of times before reaching a conclusion. In order to discuss certain points in the emerging paintings, the teacher often diplayed the students' works during the lesson. I found the students both enjoyed and learned a great deal from these discussions. It was an insight for me to realize how much the students read into their works, and how strong the power of visual suggestion can be, especially in works of an experimental nature.

In conclusion, what I basically found was that the art experience at this level is an extremely rich experience for all involved. While other research methodologies can probe certain aspects of this vast complexity, a phenomenological approach holds a unique position in that it allows the researcher to inquire into the experiential totality which makes up the art teaching/learning environment.

\section{Reference}

Reeder, H. P. (1986). The theory and practice of Husserl's phenomenology. Lanham, MD: University Press of America. 